\title{
Technical Note \\ Short-Term Storability of Alginate-Encapsulated Persian Violet Microshoots for Germplasm Exchange
}

\author{
Saowaros Phanomchai ${ }^{1}$, Kitti Bodhipadma ${ }^{1}\left(\mathbb{0}\right.$, Sompoch Noichinda ${ }^{1}\left(\mathbb{C}\right.$ and David W. M. Leung ${ }^{2, *(1)}$ \\ 1 Division of Agro-Industrial Technology, Faculty of Applied Science, King Mongkut's University of \\ Technology North Bangkok, Bangsue, Bangkok 10800, Thailand; ph.saowaros@gmail.com (S.P.); \\ kitti.b@sci.kmutnb.ac.th (K.B.); sompoch.n@sci.kmutnb.ac.th (S.N.) \\ 2 School of Biological Sciences, University of Canterbury, Private Bag 4800, Christchurch 8140, New Zealand \\ * Correspondence: david.leung@canterbury.ac.nz
}

Citation: Phanomchai, S.; Bodhipadma, K.; Noichinda, S.; Leung, D.W.M. Short-Term Storability of Alginate-Encapsulated Persian Violet Microshoots for Germplasm Exchange. Plants 2022, 11, 185. https://doi.org/10.3390/ plants11020185

Academic Editor: Praveen K. Saxena

Received: 15 December 2021

Accepted: 6 January 2022

Published: 11 January 2022

Publisher's Note: MDPI stays neutral with regard to jurisdictional claims in published maps and institutional affiliations.

Copyright: (C) 2022 by the authors. Licensee MDPI, Basel, Switzerland. This article is an open access article distributed under the terms and conditions of the Creative Commons Attribution (CC BY) license (https:// creativecommons.org/licenses/by/ $4.0 /)$.

\begin{abstract}
Microshoots have been widely used for micropropagation. It may be necessary to store microshoots for a short period of time, for example in germplasm exchange needing transport to other research groups. Here, we investigated the short-term storability of alginate-encapsulated Persian violet (Exacum affine Balf. f. ex Regel) microshoots at $4{ }^{\circ} \mathrm{C}$ and $25{ }^{\circ} \mathrm{C}$. After storage, the encapsulated microshoots were sown on basal Murashige and Skoog medium for germination and viability determination using tetrazolium chloride staining. The results showed that one or five microshoots encapsulated with a single alginate layer could be stored at $4{ }^{\circ} \mathrm{C}$ for up to 30 days, while the percentages of germination and viability of the microshoots encapsulated with two layers of alginate were greatly reduced upon storage. This is the first report on the storability of alginateencapsulated multiple microshoots, which could be a more efficient way to encapsulate microshoots used for short-term cold storage.
\end{abstract}

Keywords: Exacum affine; encapsulation; in vitro conservation; synthetic seed; plant tissue culture

\section{Introduction}

Somatic embryos or non-embryonic propagules such as microshoots can be encapsulated using an alginate-based protocol to assist mass micropropagation of plants, particularly the sowing into an ex-vitro growing substrate [1-4]. If required, the encapsulated propagules or commonly called "synthetic seeds," could possibly be used to facilitate short-term storage required for germplasm exchange or delayed sowing $[5,6]$. In most studies on synthetic seeds, a plant propagule is often enclosed within a single alginate coating $[7,8]$, while variations of this approach, including double coating layers, have also been investigated [9-12].

Persian violet (Exacum affine Balf. f. ex Regel) with its eye-catching purple flowers is popular for decorative purposes in Thailand and is mainly propagated vegetatively because propagation by seeds reduces this plant's fertility [13]. Micropropagation via microshoots encapsulated with a single alginate coating may be an additional tool to assist mass vegetative propagation of Persian violet $[4,14]$ and short-term storage for germplasm exchange. It is, therefore, of interest to investigate the effect of alginate coating on the short-term storability of encapsulated Persian violet microshoots at $4{ }^{\circ} \mathrm{C}$ and $25^{\circ} \mathrm{C}$ for up to 60 days. During an increased time in storage, there would be some humidity loss from the encapsulated microshoot, which would affect its viability and emergence out of the coating. A double-layer coating was hypothesized to better protect the microshoot during storage than a single-layer one because there would be more alginate hydrogel and a higher water content in the double coating.

Aromatic rice microshoots (size of 3-5 $\mathrm{mm}$ ) encapsulated with a single alginate layer could be kept at $4{ }^{\circ} \mathrm{C}$ for 30 days [15], while $4-8 \mathrm{~mm}$ Begonia microshoot in single-layer 
encapsulation was able to be kept for up to 56 days [16], suggesting that a larger encapsulated structure could be kept for a longer time than a smaller one. We also investigated this possibility with encapsulated Persian violet microshoots. Since, in our previous study [14], it was found that Persian violet microshoots of the size of $2-3 \mathrm{~mm}$ were preferable for micropropagation, we compared the storability of a synthetic seed (a microshoot of 2-3 mm encapsulated with a single layer of alginate) and a larger encapsulated structure (termed herewith as synthetic fruit) with five microshoots each of $2-3 \mathrm{~mm}$. The emergernce or 'germination' of a single microshoot from the artificial alginate coating is analogous to the embryo which emerges from a true seed and hence the encapsulated microshoot is termed herewith as a synthetic seed. In a naturally formed fruit there might be more than one seed and hence the term used herewith a 'synthetic fruit' for several microshoots encapsulated in alginate more resembles a true fruit.

In particular, we investigated the effects of the respective coating approaches on the emergence rate of the microshoots out of the alginate coating ('germination of synthetic seeds and synthetic fruit,' respectively) after storage at two different temperatures for various times.

\section{Results and Discussion}

\subsection{Alginate Encapsulation}

In this study, the diameters of the synthetic seed with a single and double alginate coating were about $5-6 \mathrm{~mm}$ and $7-8 \mathrm{~mm}$, respectively (Figure 1 ). These were similar to those reported in other studies [12,17-20]. The diameter of the synthetic Persian violet fruit (10-11 mm) was higher than the synthetic seed. As far as we know, this is the first report of this variation of alginate encapsulation of microshoots or other propagules.

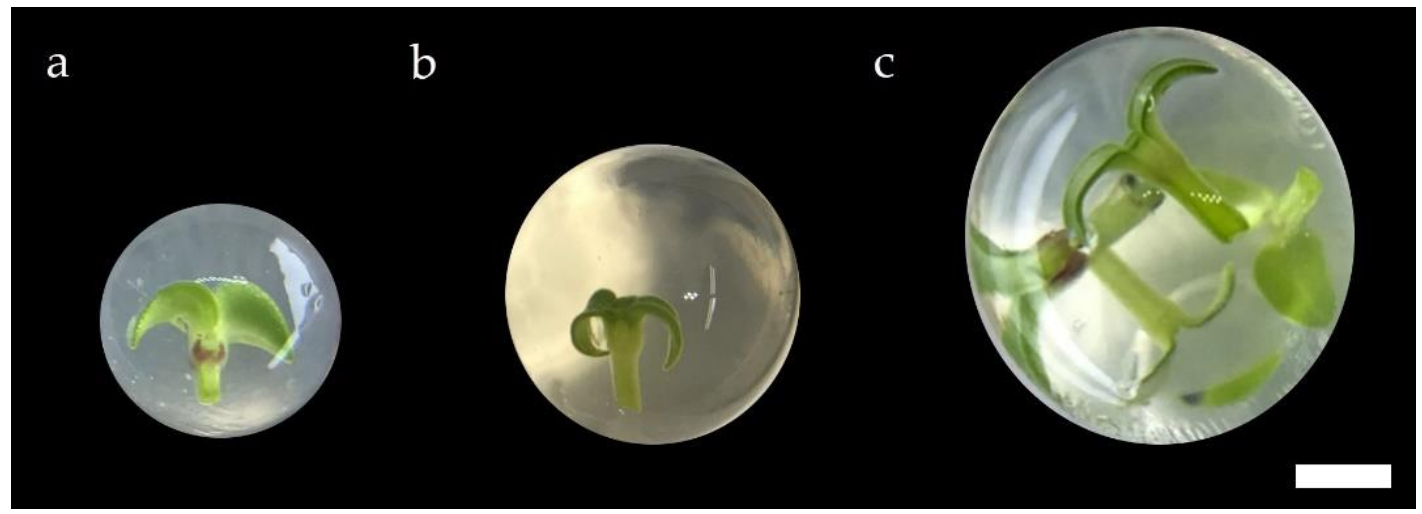

Figure 1. Appearance of alginate-encapsulated structures ((a): a Persian violet microshoot encapsulated with a single layer of alginate (a synthetic seed); (b): a microshoot encapsulated with a double layer of alginate (a synthetic seed); (c): five microshoots encapsulated within a single layer of alginate (a synthetic fruit); scale bar $=2 \mathrm{~mm}$ ).

\subsection{Germination and Viability Assessment}

It was found that double alginate coating resulted in a substantially reduced germination rate (less than $50 \%$ ) of Persian violet microshoots compared to a single coating prior to any storage treatment (Figure 2). After storage at $4{ }^{\circ} \mathrm{C}$ and $25{ }^{\circ} \mathrm{C}$ for up to 30 days, the microshoots encapsulated in double coating exhibited the lowest germination percentage compared to those in single coating encapsulating one or five microshoots (Figure S1 and Figure 2). Interestingly, there was no significant difference in the post-storage germination rates of the microshoots encapsulated individually in a single layer and the synthetic fruit. However, the apple and banana synthetic seeds encapsulated in a single alginate coating did not exhibit substantially different germination percentages than synthetic seeds with double alginate coating $[11,12,17]$. The effect of double coating on the storability of these synthetic seeds was also not the focus of these studies. 
In general, after storage at $4{ }^{\circ} \mathrm{C}$, all three encapsulated structures in the present study exhibited higher germination percentages than at $25^{\circ} \mathrm{C}$. It was also found that no encapsulated Persian violet microshoot was able to protrude out of the alginate coating after 60 days of storage at $4{ }^{\circ} \mathrm{C}$ and $25^{\circ} \mathrm{C}$ (Figure 2 and Figure S2). This finding was similar to those of previous studies [21-24].

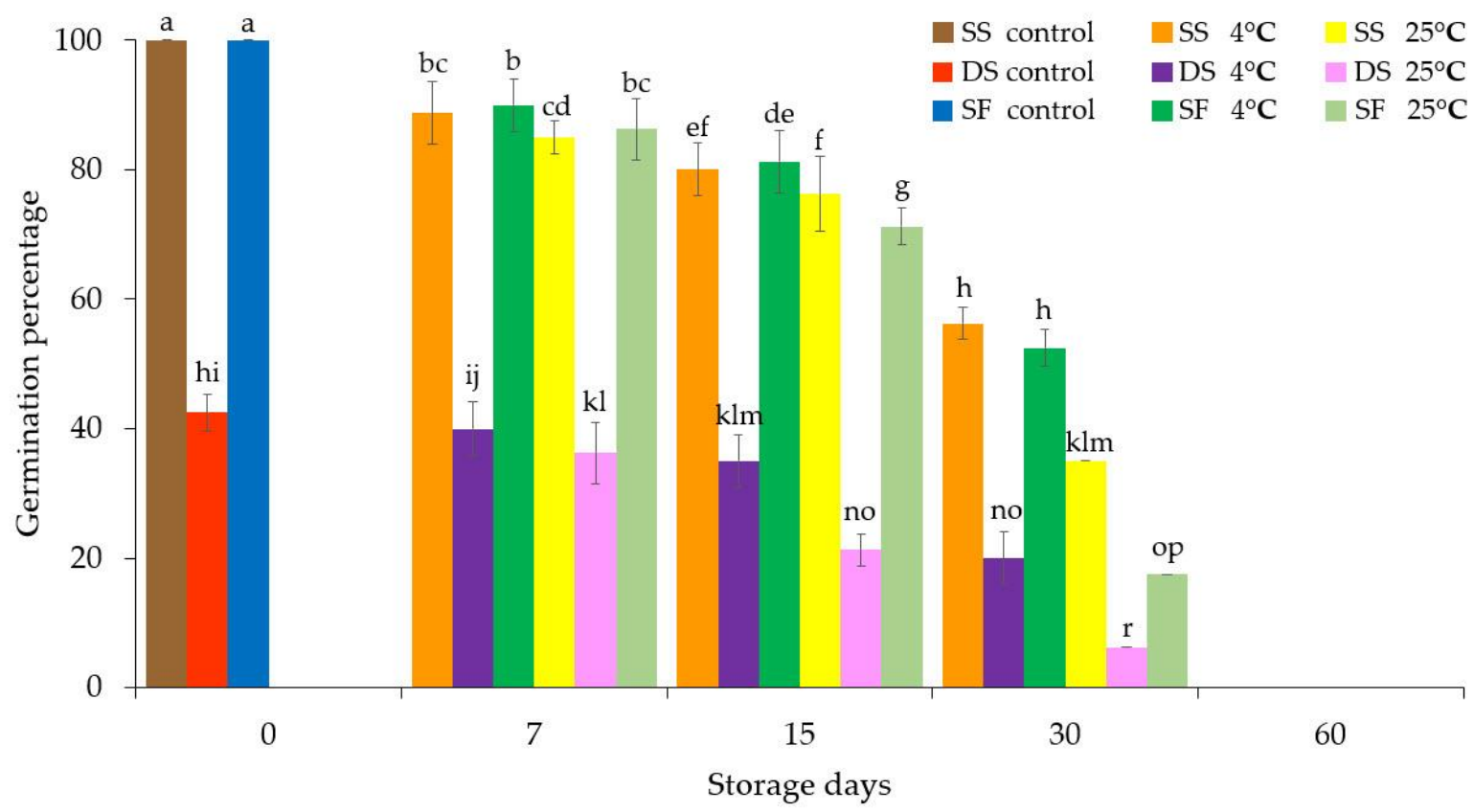

Figure 2. Germination percentages after synthetic seeds and fruit of Persian violet were stored at $4{ }^{\circ} \mathrm{C}$ and $25{ }^{\circ} \mathrm{C}$ for $0,7,15,30$ and 60 days. SS: a microshoot (synthetic seed) encapsulated with a single layer of alginate, DS: a single microshoot (synthetic seed) encapsulated with a double layer of alginate, SF: five microshoots encapsulated with a single layer of alginate (synthetic fruit). Data were means \pm SD and those with different letters were significantly different $(p<0.05)$.

Different kinds of encapsulated propagules might respond differently to short-term cold storage. For example, the encapsulated somatic embryos of eggplant and Catharanthus roseus could be stored for 45 , and 75 days, respectively $[8,25]$, the encapsulated protocorms of Cymbidium aloifolium and the nodal buds of Aquilaria malaccensis could be stored for 90 days and 60 days, respectively [24,26]. The encapsulated microshoots of rice could be stored at $4{ }^{\circ} \mathrm{C}$ for 30 days [15], while those of Begonia and Nerium oleander could be stored at $4{ }^{\circ} \mathrm{C}$ for 56 days $[16,27]$. Overall, choosing the kind of propagule for encapsulation might be considered one of the factors for short-term low-temperature storage of plant germplasm in vitro.

The percentages of viable microshoots in the synthetic Persian violet seeds or fruit were determined using tetrazolium tetrachloride staining decreased with increasing storage times at $4{ }^{\circ} \mathrm{C}$ and $25^{\circ} \mathrm{C}$ (Figure 3 and Figure S3). This result was consistent with the finding of the germination percentages of synthetic seeds and fruit (Figure 2). However, double coating did not affect the viability of the encapsulated microshoots as revealed by tetrazolium tetrachloride viability staining. In this study, our present results will lead to future research of cryopreservation of the synthetic Persian violet seeds or fruit; for example, encapsulation-dehydration or encapsulation-vitrification, which has more benefit for long-term germplasm conservation [28-30]. 


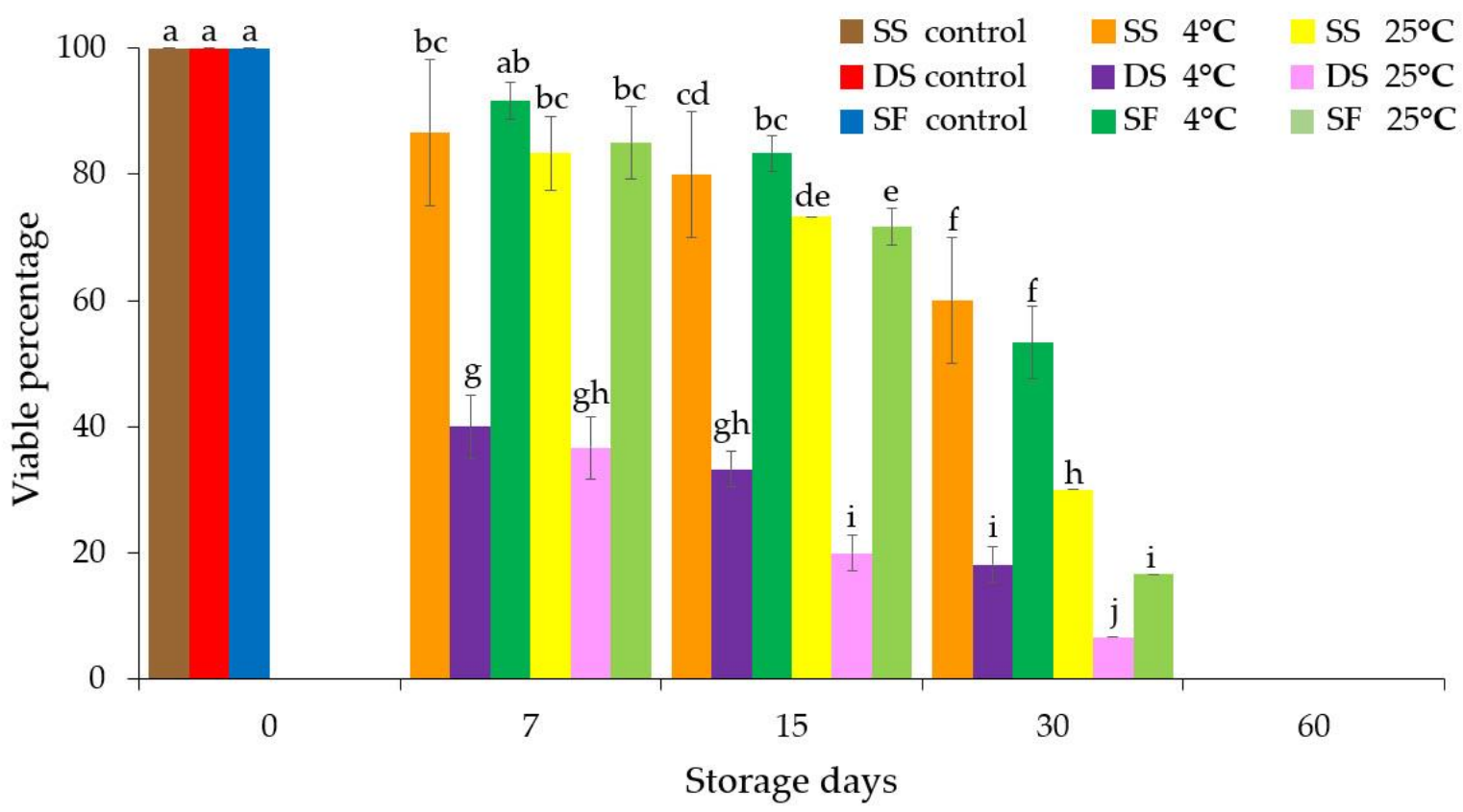

Figure 3. Percentages of viable Persian microshoots from synthetic seeds and fruit after storage at $4{ }^{\circ} \mathrm{C}$ and $25^{\circ} \mathrm{C}$ for $0,7,15,30$ and 60 days. The viability test was based on staining the microshoots with $1 \%(w / v)$ 2,3,5-triphenyltetrazolium chloride. SS: a microshoot (synthetic seed) encapsulated with a single layer of alginate, DS: a single microshoot (synthetic seed) encapsulated with a double layer of alginate, SF: five microshoots encapsulated with a single layer of alginate (synthetic fruit). Data were means $\pm \mathrm{SD}$ and those with different letters were significantly different $(p<0.05)$.

\section{Materials and Methods}

\subsection{Plant Materials}

In vitro Persian violet plantlets were obtained and micropropagated as described previously [14]. Microshoots (2-3 $\mathrm{mm}$ long) were excised from the in vitro Persian violet plantlets and were then used for alginate encapsulation in this study.

\subsection{Encapsulation of Microshoots}

Persian violet microshoots were cut under aseptic conditions and then submerged in a $120 \mathrm{~mL}$ jar containing $25 \mathrm{~mL}$ of $3 \%(w / v)$ sodium alginate dissolved in basal liquid MS medium [31] supplemented with $3 \%$ sucrose. Using a $1000 \mu \mathrm{L}$ micropipette (Mettler Toledo, Columbus, OH, USA) fitted with a micropipette tip (Axygen Scientific, Inc., Union City, CA, USA) that had been cut so that the inside diameter was $6 \mathrm{~mm}$, five microshoots with the sodium alginate solution were drawn into the tip of the micropipette. The microshoots were then pushed out one by one in the case of generating synthetic seeds (Figure 1a,b), or the five microshoots were pushed out all at once in the case of generating synthetic fruit (Figure 1c), into a $240 \mathrm{~mL}$ jar containing $50 \mathrm{~mL}$ of $1 \%(w / v)$ calcium chloride dissolved in basal liquid MS medium supplemented with $3 \%$ sucrose. This procedure was repeated until 20 spherical synthetic seeds or synthetic fruit, each with a microshoot or five microshoots, respectively, were generated. The jar was shaken gently for $30 \mathrm{~min}$ before the synthetic seeds or synthetic fruit were rinsed with $50 \mathrm{~mL}$ of basal liquid MS medium supplemented with $3 \%$ sucrose in a $240 \mathrm{~mL}$ jar for $1 \mathrm{~min}$. Some of the synthetic seeds with a single alginate layer were used to generate synthetic seeds with a double (second additional) layer of alginate (Figure 1b).

\subsection{Storage Experiments and In Vitro Culture}

During storage at $4^{\circ} \mathrm{C}$ and $25^{\circ} \mathrm{C}, 20$ synthetic seeds or four synthetic fruit were kept in a $120 \mathrm{~mL}$ jar for $0,7,15,30$, and 60 days under aseptic, dark and controlled humidity 
conditions. After storage, a synthetic seed was transferred separately to a jar with basal semi-solid MS medium. For the synthetic fruit after storage, each microshoot with alginate coating was cut and transferred separately to a jar with basal semi-solid MS medium. All the synthetic seeds and microshoots from the synthetic fruit were cultured for 4 weeks in a growth room under light $\left(20.87 \mu \mathrm{mol} / \mathrm{m}^{2} / \mathrm{s}\right)$ and dark periods (16/8 $\mathrm{h}$, respectively) at $25 \pm 2{ }^{\circ} \mathrm{C}$. In this experiment, there were 4 replicates and 20 alginate-encapsulated structures in each replicate.

\subsection{Germination and Viability Assessment of Synthetic Seed and Synthetic Fruit}

At the end of in vitro culture, the number of microshoots that grew ('germinated') out of the alginate coating was counted to determine germination percentage according to Dewir et al. [32] using the following formula.

Germination percentage $(\mathrm{GP})=$ (number of germinated microshoot from synthetic seeds and fruit/number of tested microshoots) $\times 100$

For viability determination, each microshoot was removed from the coating and dissected slightly at the base to remove the attached calcium-alginate. Five microshoots were placed in a Petri dish containing $20 \mathrm{~mL}$ of $1 \%(w / v)$ 2,3,5-triphenyltetrazolium chloride for $24 \mathrm{~h}$. A viable microshoot would turn red [33]. There were 3 replications and 10 synthetic seeds or synthetic fruit in each replication of the different storage treatments.

\subsection{Statistical Analysis}

The statistical software SPSS version 26 (IBM, Chicago, IL, USA), was used for data analysis. Differences of mean in the germination percentage and viability percentage of microshoots from the synthetic seeds and synthetic fruit of Persian violet were analyzed using Duncan's Multiple Range Test $(p<0.05)$.

\section{Conclusions}

This research showed that storage of synthetic Persian violet seed and synthetic fruit with a single alginate coating is better at $4{ }^{\circ} \mathrm{C}$ than at $25^{\circ} \mathrm{C}$. If required, synthetic Persian violet seed and synthetic fruit with a single alginate coating could be stored at $4{ }^{\circ} \mathrm{C}$ for a short time (up to 30 days). Moreover, generating the synthetic fruit for cold storage would be a more efficient encapsulation procedure than encapsulating individual microshoots to generate synthetic seeds. The double alginate encapsulation approach is not suitable for cold storage of Persian violet microshoots.

Supplementary Materials: The following are available online at https:/ / www.mdpi.com/article / 10.3390/plants11020185/s1, Figure S1: Characteristic of 4-week-old Persian violet plantlet grown out of encapsulated structure after storage at $4{ }^{\circ} \mathrm{C}$ for 7 days (a: single layer encapsulated synthetic seed; b: double layer encapsulated synthetic seed; $c$ : synthetic fruit; scale bar $=1 \mathrm{~cm}$ ).; Figure S2: Characteristic of non-viable Persian violet microshoots in synthetic fruit stored at $4{ }^{\circ} \mathrm{C}$ for 60 days (scale bar $=2 \mathrm{~mm}$ ). Figure S3: Characteristic of Persian violet microshoot from synthetic fruit after stained with triphenyltetrazolium chloride (a: stored at $4{ }^{\circ} \mathrm{C}$ for 15 days; b: stored at $25^{\circ} \mathrm{C}$ for 60 days; scale bar $=2 \mathrm{~mm}$ ).

Author Contributions: Conceptualization, K.B. and S.N.; methodology, K.B.; validation, K.B., S.N. and D.W.M.L.; formal analysis, K.B. and S.P.; investigation, K.B. and S.P.; writing-original draft preparation, K.B., D.W.M.L. and S.P.; writing-review and editing, K.B., D.W.M.L. and S.P. All authors have read and agreed to the published version of the manuscript.

Funding: This research received no external funding.

Institutional Review Board Statement: Not applicable.

Informed Consent Statement: Not applicable.

Data Availability Statement: Data are contained within the article and Supplementary Materials.

Conflicts of Interest: The authors declare no conflict of interest. 


\section{References}

1. Murashige, T. The impact of plant tissue culture on agriculture. In Frontiers of Plant Tissue Culture; Thorpe, T.A., Ed.; Calgary University Press: Calgary, AB, Canada, 1978; pp. 15-26.

2. Sharma, S.; Shahzad, A.; da Silva, J.A.T. Synseed technology-A complete synthesis. Biotechnol. Adv. 2013, 31, 186-207. [CrossRef]

3. Rihan, H.Z.; Kareem, F.; El-Mahrouk, M.E.; Fuller, M.P. Artificial seeds (principle, aspects and applications). Agronomy 2017, 7, 71. [CrossRef]

4. Sukthavornthum, W.; Bodhipadma, K.; Noichinda, S.; Phanomchai, S.; Deelueak, U.; Kachonpadungkitti, Y.; Leung, D.W.M. UV-C irradiation induced alterations in shoot proliferation and in vitro flowering in plantlets developed from encapsulated and non-encapsulated microshoots of Persian violet. Sci. Hortic. 2018, 233, 9-13. [CrossRef]

5. Gantait, S.; Kundu, S. Artificial seed technology for storage and exchange of plant genetic resources. In Advanced Technologies for Crop Improvement and Agricultural Productivity; Malik, C.P., Wani, S.H., Kushwaha, H.B., Kaur, R., Eds.; Agrobios (International): Jodhpur, India, 2017; pp. 135-159.

6. Gantait, S.; Vijayan, J.; Majee, A. Artificial seed production of Tylophora indica for interim storing and swapping of germplasm. Hort. Plant J. 2017, 3, 41-46. [CrossRef]

7. Nieves, N.; Lorenzo, J.C.; Blanco, M.D.; Gonzalez, J.; Peralta, H.; Hernandez, M.; Santos, R.; Concepcion, O.; Borroto, C.G.; Borroto, E.; et al. Artificial endosperm of Cleopatra tangerine zygotic embryos: A model for somatic embryo encapsulation. Plant Cell Tissue Organ Cult. 1998, 54, 77-83. [CrossRef]

8. Huda, A.K.M.N.; Rahman, M.; Bari, M.A. Effect of carbon source in alginate bead on synthetic seed germination in eggplant (Solanum melongena L.). J. Plant Sci. 2007, 2, 538-544. [CrossRef]

9. Saha, M.; Phatak, A.; Chandra, N. Generation of synthetic seeds from different varieties of Carica papaya L. J. Tissue Res. 2004, 4, 207-209.

10. Pinker, I.; Abdel-Rahman, S.S.A. Artificial seeds for propagation of Dendranthema $\times$ grandiflora (Ramat.). Propag. Ornam. Plants 2005, 5, 186-191.

11. Sandoval-Yugar, E.W.; Vesco, L.L.D.; Steinmacher, D.A.; Stolf, E.C.; Guerra, M.P. Microshoots encapsulation and plant conversion of Musa sp. cv. 'Grand Naine'. Cienc. Rural 2009, 39, 998-1004. [CrossRef]

12. Hassanein, A.; Ibraheim, I.A.; Galal, A.-N.; Salem, J. Conversion of banana synseed influenced by the bead type and seed coat. Am. J. Plant Sci. 2011, 2, 467-475. [CrossRef]

13. Ørnstrup, H.; MØlgaard, J.P.; Farestveit, B. Somatic embryogenesis and plant regeneration from cell suspensions of Exacum affine. Plant Cell Tissue Organ Cult. 1993, 35, 37-41. [CrossRef]

14. Sarai, N.; Bodhipadma, K.; Noichinda, S.; Luangsriumporn, P.; Leung, D.W.M. Microshoot culture of Persian violet: Plant regeneration and in vitro flowering. Ann. Agric. Sci. 2017, 62, 105-111. [CrossRef]

15. Taha, R.M.; Saleh, A.; Mahmad, N.; Hasbullah, N.A.; Mohajer, S. Germination and plantlet regeneration of encapsulated microshoots of aromatic rice (Oryza sativa L. cv. MRQ 74). Sci. World J. 2012, 2012, 578020.

16. Sakhanokho, H.F.; Pounders, C.T.; Blythe, E.K. Alginate encapsulation of Begonia microshoots for short-term storage and distribution. Sci. World J. 2013, 2013, 341568. [CrossRef] [PubMed]

17. Micheli, M.; Pellegrino, E.; Piccioni, E.; Standadi, A. Effect of double encapsulation and coating on synthetic seed conversion in M.26 apple rootstock. J. Microencapsul. 2002, 19, 347-356. [CrossRef] [PubMed]

18. Daud, N.; Taha, R.M.; Hasbullah, N.A. Artificial seed production from encapsulated micro shoots of Saintpaulia ionantha Wendl (African violet). J. Appl. Sci. 2008, 8, 4662-4667. [CrossRef]

19. Rihan, H.Z.; Al-Issawi, M.; Burchett, S.; Fuller, M.P. Artificial seed production from encapsulated microshoots of cauliflower (Brassica oleraceae var botrytis). Acta. Hort. 2012, 961, 419-425. [CrossRef]

20. Siong, P.K.; Mohajer, S.; Taha, R.M. Production of artificial seeds derived from encapsulated in vitro micro shoots of cauliflower, Brassica oleracea var. botrytis. Rom. Biotechnol. Lett. 2012, 17, 7549-7556.

21. Mohanraj, R.; Ananthan, R.; Bai, V.N. Production and storage of synthetic seeds in Coelogyne breviscapa Lindl. Asian J. Biotechnol. 2009, 1, 124-128. [CrossRef]

22. Ikhlaq, M.; Hafiz, I.A.; Micheli, M.; Ahmad, T.; Abbasi, N.A.; Standardi, A. In vitro storage of synthetic seeds: Effect of different storage conditions and intervals on their conversion ability. Afr. J. Biotechnol. 2010, 9, 5712-5721.

23. Ma, X.M.; Wu, C.F.; Wang, G.R. Application of artificial seeds in rapid multiplication of Pseudostellaria heterophylla. Afr. J. Biotechnol. 2011, 10, 15744-15748. [CrossRef]

24. Pradhan, S.; Tiruwa, B.L.; Subedee, B.R.; Pant, B. Efficient plant regeneration of Cymbidium aloifolium (L.) Sw., a threatened orchid of Nepal through artificial seed technology. Am. J. Plant Sci. 2016, 7, 1964-1974. [CrossRef]

25. Maqsood, M.; Mujib, A.; Siddiqui, Z.H. Synthetic seed development and conservation to plantlet in Catharanthus roseus (L.). G Don. Biotechnology 2012, 11, 37-43. [CrossRef]

26. Devi, S.D.; Kharsahnoh, B.; Kumaria, S.; Das, M.C. Artificial seed for short-term storage: Using nodal buds in Aquilaria malaccensis Lam. Curr. Sci. 2018, 115, 2103-2109. [CrossRef]

27. Hatzilazarou, S.; Kostas, S.; Economou, A.S. Plant regeneration of Nerium oleander L. from alginate-encapsulated shoot explants after short-term cold storage. J. Hort. Sci. Biotechnol. 2018, 2018, 441-447. [CrossRef]

28. Kulus, D.; Rewers, M.; Serocka, M.; Mikuła, A. Cryopreservation by encapsulation-dehydration affects the vegetative growth of chrysanthemum but does not disturb its chimeric structure. Plant Cell Tiss. Organ Cult. 2019, 138, 153-166. [CrossRef] 
29. Sakai, A.; Engelmann, F. Vitrification, encapsulation-vitrification and droplet-vitrification: A review. CryoLetters 2007, 28, 151-172.

30. Valdés, Y.C.; Shukla, M.R.; González Vega, M.E.; Saxena, P.K. Improved conservation of coffee (Coffea arabica L.) germplasm via micropropagation and cryopreservation. Agronomy 2021, 11, 1861. [CrossRef]

31. Murashige, T.; Skoog, F. A revised medium for rapid growth and bio assays with tobacco tissue cultures. Physiol. Plant 1962, 15, 473-497. [CrossRef]

32. Dewir, Y.H.; El-Mahrouk, M.E.-S.; Naidoo, Y. Effects of some mechanical and chemical treatments on seed germination of Sabal palmetto and Thrinax morrisii palms. Aust. J. Crop Sci. 2011, 5, 248-253.

33. Patil, V.N.; Dadlani, M. Tetrazolium test for seed viability and vigour. In Handbook of Seed Testing; Agrawal, P.K., Ed.; Dept of Agriculture \& Co-operation, Ministry of Agriculture, Govt of India: New Delhi, India, 1993; pp. 209-241. 